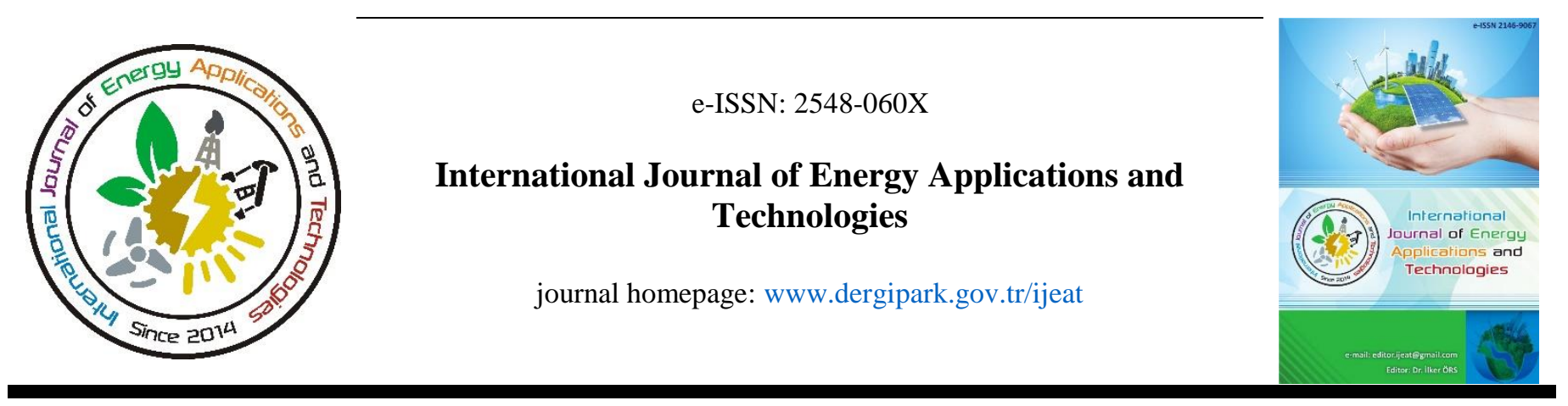

Original Research Article

\title{
Performance analysis of vapor compression refrigeration system using mixed refrigerant $R 410 A$
}

\author{
Bayram Kılıç ${ }^{1 *}$ Osman İpek ${ }^{2}$ \\ ${ }^{I}$ Program of Electricity and Energy, Vocational School of Technical Sciences, Burdur Mehmet Akif Ersoy University, Burdur, Turkey \\ ${ }^{2}$ Mechanical Engineering Department, Faculty of Engineering, Süleyman Demirel University, Isparta, Turkey
}

\author{
ARTICLE INFO \\ * Corresponding author \\ bayramkilic@mehmetakif.edu.tr \\ Received January 28, 2021 \\ Accepted May 24, 2021 \\ Published by Editorial Board \\ Members of IJEAT \\ (C) This article is distributed by \\ Turk Journal Park System under \\ the CC 4.0 terms and conditions.

\begin{abstract}
Mixed refrigerants are obtained from mixing pure refrigerants in specific proportions and it is known as mixed refrigerants. Mixture refrigerants are divided into two groups according to their thermodynamic behavior: zeotropic mixtures and azeotropic mixtures. In this study, the performance of R410A refrigerant obtained from mixture of two pure refrigerants (R125 and $\mathrm{R} 32$ ) in vapor compression refrigeration cycle was investigated. The coefficients of performance (COP) of the cooling system under different operating conditions were investigated. The highest COP value for working conditions in this study was determined as 7.3. In addition, the capacity of the cooling system compressor has been determined for different operating conditions.
\end{abstract}

\section{Introduction}

Fluids used in refrigeration cycles are called refrigerants. Basic properties expected from these fluids; low phase change temperatures, compatible with lubricating oil, nonflammable, non-explosive and non-corrosive, non-corrosive, cheap and easily available. Fluids formed by mixing pure refrigerants in certain proportions are called mixing fluids. Mixed refrigerants are divided into two groups as zeotropic mixtures and azeotropic mixtures according to their thermodynamic behavior. Changes in the state of azeotropic mixtures, ie evaporation and condensation, take place under constant temperature, while zeotropic mixtures take place under varying temperatures. Therefore, zeotropic mixtures have positive effects on cooling system performance.

The most commonly used cooling system according to the cooling need and purpose is vapor compression cooling systems. The vapor compression refrigeration cycles consist of the following processes;

- Compressor; isentropic compression (1-2)

- Condenser; heat transfer at constant pressure (2-3)

- Expansion valve; constant enthalpy expansion (3-4)

- Evaporator; heat transfer at constant pressure (4-1)

Tejaswi et al. have investigated mechanical performance of compressor of domestic cooler for two refrigerants (R-290 and R-600a). Their study aims that to determine effective compressors for domestic cooling systems [2]. Ki-Jung et al. have investigated thermal performance of refrigeration system with using refrigerants of R290 and R1270 instead of R22. Results of their study shows that these refrigerants provide good performance for air-conditioning and heat pumping applications [3]. Luiz et al. carried out thermodynamic performance of cascade cooling system for 3 different mixed refrigerants (R744/R1270, R744/R717 and 
R744/RE170). It is determinated in study that R744/RE170 mixture refrigerant obtained the best results with a COP of 2.34 [4]. Jatinder and Jagdev have examinated performance of vapor compression cooling system using a mixture of R134a and LPG refrigerant. Their study shows that mixture of R134a and LPG refrigerant has good performed better compared with R134A [5]. Kılıçarslan et al. examined COP

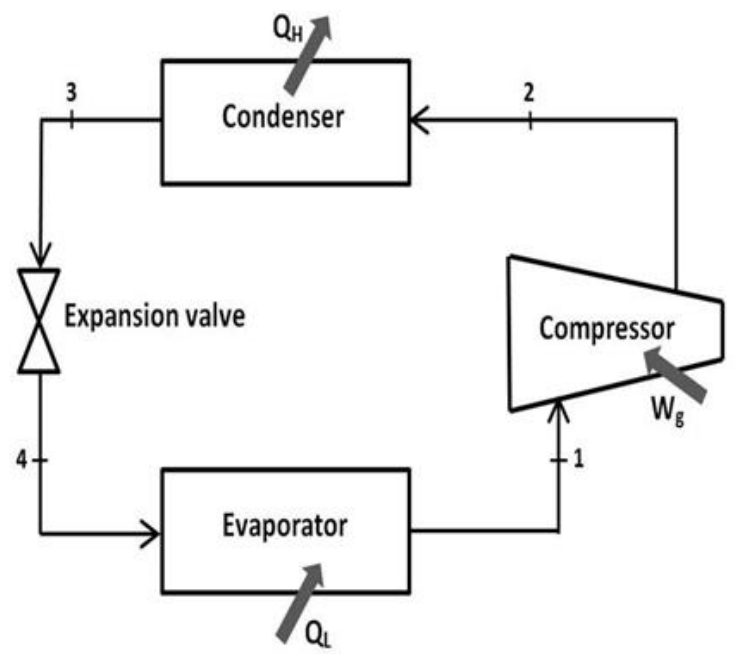

of cooling system for different evaporator and condenser temperatures using azeotropic refrigerants such as R502, R507A and R500, near azeotropic refrigerants such as R404A and R410A [6]. Y1lmaz et al. investigated COP of ejector cooling systems as theoretically [7]. Kılıç et al. examined performance of two-stage with economizer refrigeration System [8].

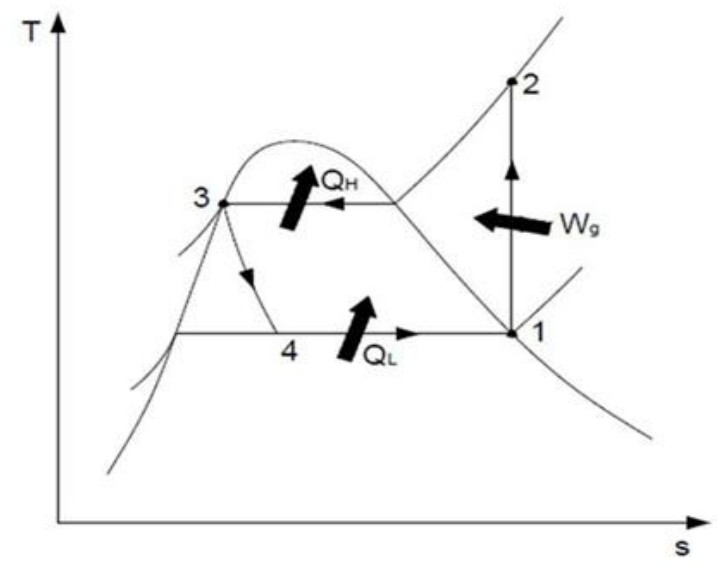

Fig.1. Schematic representation of the vapor compression refrigeration cycle and T-s diagram [1].

The purpose of this study is to show the suitability of using mixed refrigerants formed by these fluids instead of pure refrigerants used in cooling systems. In addition, it is to show that not only the performance but also the properties such as flammability, accessibility and toxicity are important in the choice of refrigerant in cooling systems.

The most important parameter that determines the characteristics of the refrigerant to be used in a cooling system is the compressor type. The second parameter is the evaporator type, also. Therefore, the refrigerant to be proposed or preferred in place of a conventional refrigerant must run smoothly in the existing compressor and provide sufficient performance. Except that, for alternative refrigerants to be proposed, suitable compressors can be designed, but in this case the cost will increase further and it will be necessary to design a new cooling system. Depending on these reasons, in determining alternative refrigerants, firstly, suitable refrigerants for existing systems should be investigated.

There are two basic concepts related to the environmental properties of refrigerants.

1. ODP (Ozone Depletion Potential): Refers to the damage that the refrigerant can cause to the ozone layer and is found as a relative value by referring to the R11 molecule whose ODP is assumed to be 1 .

2. GWP (Global Warming Potential): It is an indicator of greenhouse gas effect and global warming effect and is the relative value given with reference to carbon dioxide $\left(\mathrm{CO}_{2}\right)$ having a GWP of 1 .

Table 1 presents the properties of the refrigerants used in this study.

Table 1. Properties of refrigerants.

\begin{tabular}{cccccc}
\hline Refrigerants & $\begin{array}{c}\text { Molecular weight } \\
\left(\mathbf{k g ~ k m o l}^{\mathbf{1}}\right)\end{array}$ & $\begin{array}{c}\text { Critical temperature } \\
\left({ }^{\mathbf{}} \mathbf{C}\right)\end{array}$ & $\begin{array}{c}\text { Critical pressure } \\
(\mathbf{M P a})\end{array}$ & ODP & GWP100 \\
\hline R125 & 120 & 66.02 & 3.618 & 0 & 2800 \\
R32 & 52 & 78.11 & 5.782 & 0 & 650 \\
R410A & 72.6 & 71.35 & 4.902 & 0 & 1730 \\
\hline
\end{tabular}

\section{Material and Methods}

The following equations can be written using mass and energy conservation equations for vapor compression refrigeration system [9].

$$
\dot{m}_{1}=\dot{m}_{2}=\dot{m}_{3}=\dot{m}
$$

In the vapor compression refrigeration cycle given in Fig. 1, evaporator capacity can be calculated as follows [10]:

$$
\dot{Q}_{E}=\dot{m}\left(h_{1}-h_{4}\right)
$$


Compressor work is;

$$
\dot{W}_{\text {Comp }}=\dot{m}\left(h_{2}-h_{1}\right)
$$

Condenser capacity is;

$$
\dot{Q}_{C}=\dot{m}\left(h_{3}-h_{2}\right)
$$

COP of the vapor compression refrigeration cycle can be calculated as follows [11-12];

$$
\text { COP }=\frac{\dot{Q}_{E}}{\dot{W}_{\text {Comp }}}
$$

\section{Results and Discussion}

Cooling capacity and coefficient of performance (COP) were determined for different working conditions in the vapor compression refrigeration cycle. The condenser temperatures were kept constant and the evaporator temperatures were changed in the analyses. Variation of COP and cooling capacity depending on evaporator temperatures are given in Fig. 2 for $20{ }^{\circ} \mathrm{C}$ condenser temperature. In Fig. 2, the maximum COP value is 7.3 for R410A and 7.5 for R32 while evaporator temperature is $-5{ }^{\circ} \mathrm{C}$. In these operating conditions, the minimum COP value is 7 for R125. In Fig. 3, the condenser temperature was kept constant at $30{ }^{\circ} \mathrm{C}$. Evaporator temperatures have been changed and COP values were calculated. In Fig. 3, the maximum COP value is 6 for $\mathrm{R} 32$. This value was followed by R410A with 5.8 and R125 with 5.6.

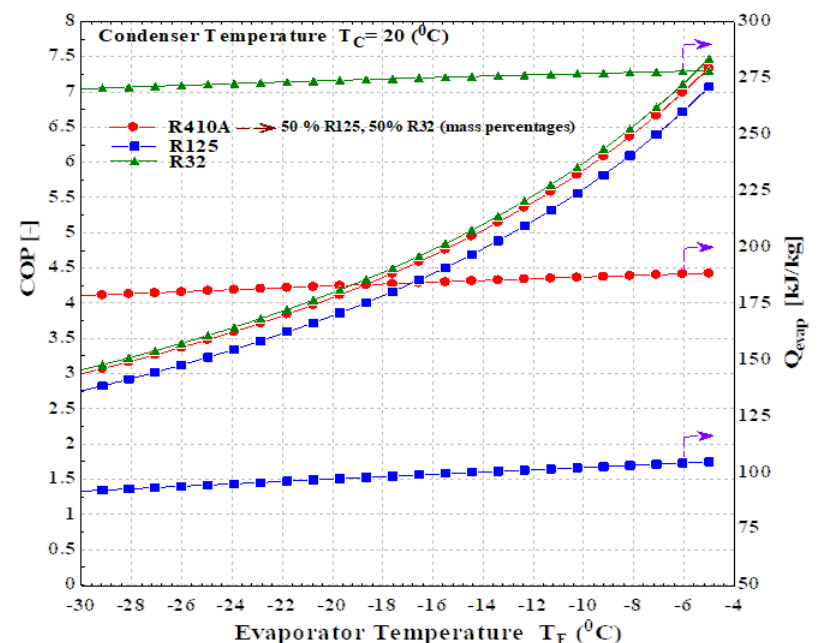

Fig. 2. Variation of COP and cooling capacity depending on evaporator temperatures

(For $\mathrm{T}_{\mathrm{c}}=20^{\circ} \mathrm{C}$ )

When Figures 4-5 and 6 are examined, it is seen that similar results are obtained. The highest COP values for the operating conditions in this study were obtained for R32 refrigerant. This refrigerant was followed by R410A and $\mathrm{R} 125$, respectively.

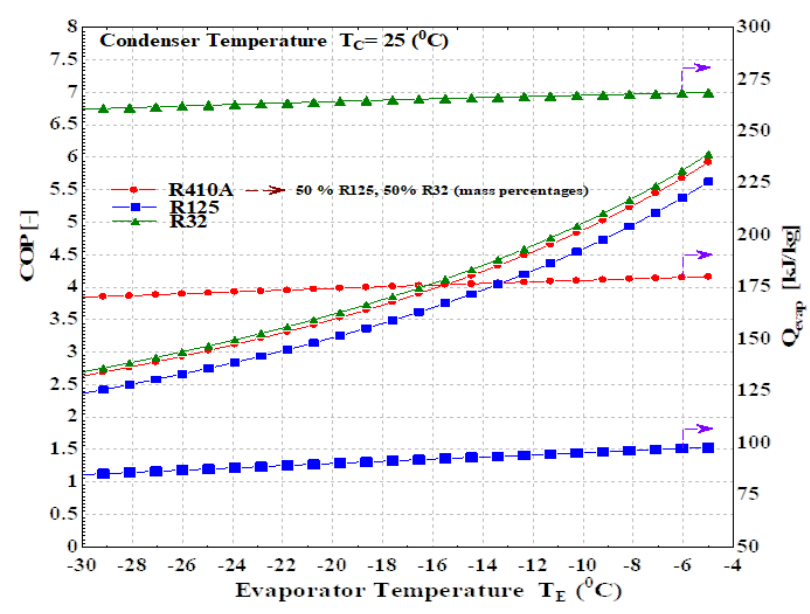

Fig. 3. Variation of COP and cooling capacity depending on evaporator temperatures

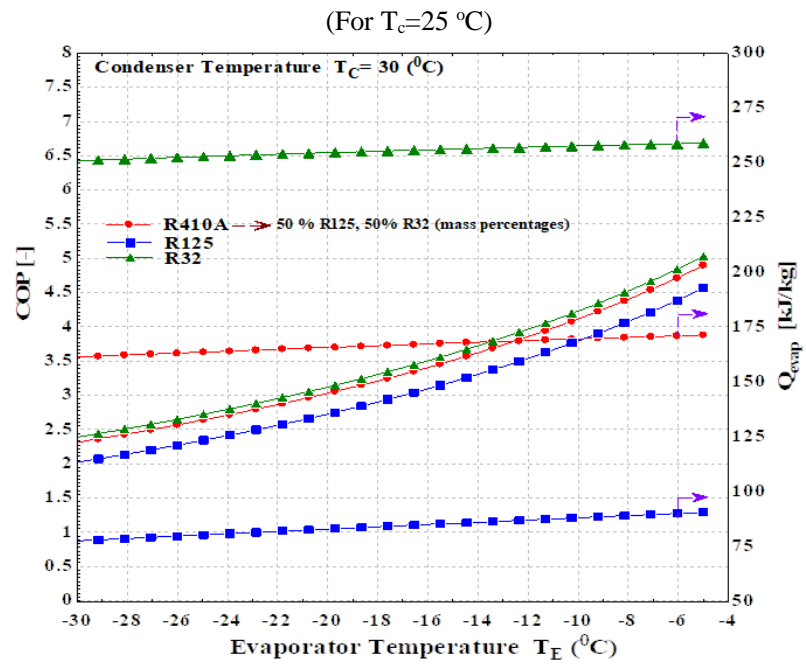

Fig. 4. Variation of COP and cooling capacity depending on evaporator temperatures

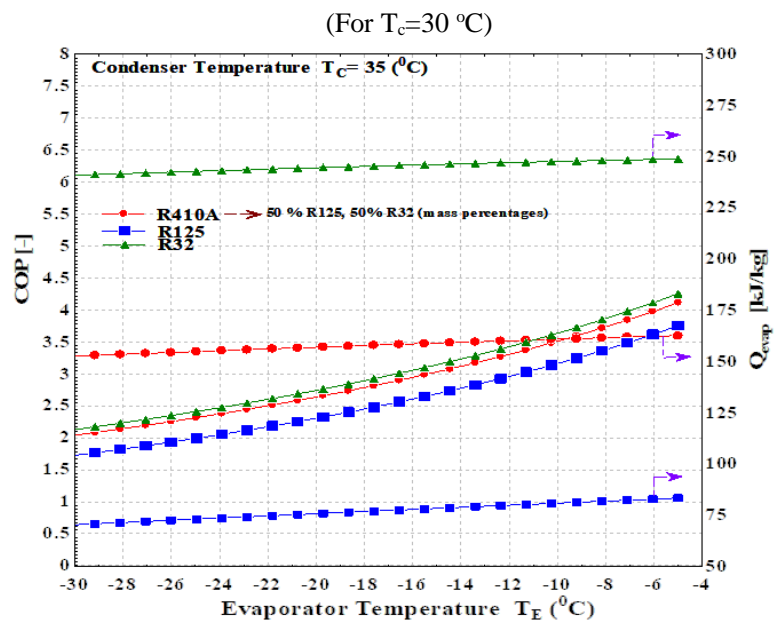

Fig. 5. Variation of $\mathrm{COP}$ and cooling capacity depending on evaporator temperatures

(For $\mathrm{T}_{\mathrm{c}}=35^{\circ} \mathrm{C}$ ) 


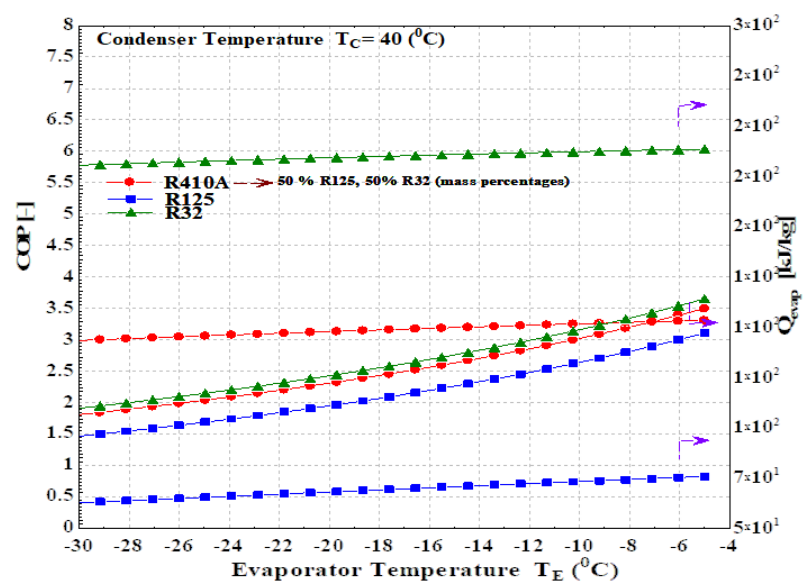

Fig. 6. Variation of COP and cooling capacity depending on evaporator temperatures

$\left(\right.$ For $\left.\mathrm{T}_{\mathrm{c}}=40{ }^{\circ} \mathrm{C}\right)$

Variation of compressor work depending on evaporator temperatures and condenser temperatures are given in Fig. 7. In Fig. 7, the highest compressor work is $120 \mathrm{~kJ} / \mathrm{kg}$ for evaporator temperature $-30{ }^{\circ} \mathrm{C}$, condenser temperature $40{ }^{\circ} \mathrm{C}$ and refrigerant R32. It is seen that the most suitable values for average compressor work is for R410A. When take into account COP values, the most appropriate value is $60 \mathrm{~kJ} / \mathrm{kg}$. The high compressor work causes both initial investment costs and operating costs.

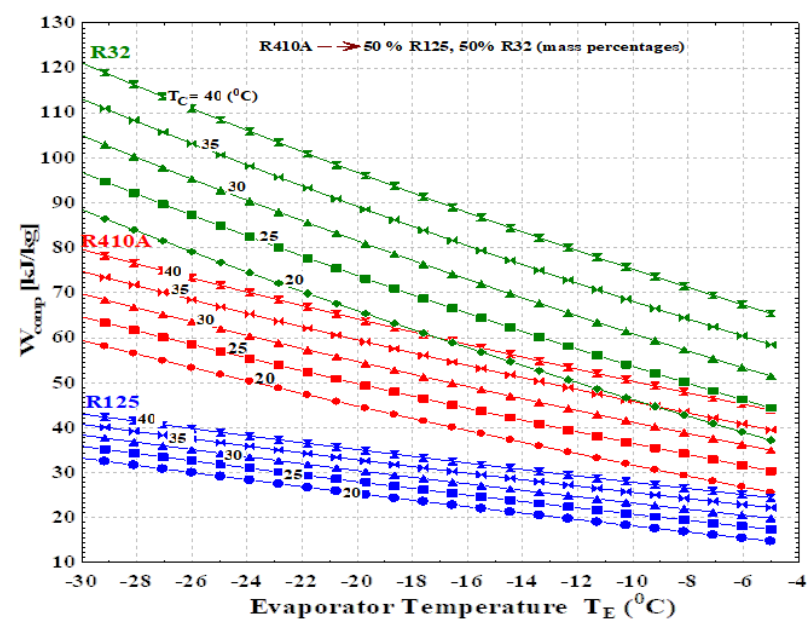

Fig. 7. Variation of compressor work depending on evaporator temperatures.

\section{Conclusion}

In this study, the performance of R410A refrigerant obtained from mixture of two pure refrigerants (R125 and R32) in vapor compression refrigeration cycle was investigated for different operating conditions. R32 has excellent thermodynamic properties as a refrigerant. But, refrigerant R32 has flammability specifications (12.7-33.4\% by volume in air). Therefore, R32 are classified as highly flammable. However, R32 is a highly suitable component for mixing refrigerants, especially for R410A. R410A is nonflammable and toxicologically safe. Also, R410A is stable as thermally and chemically. Since both the high COP value and the appropriate compressor work are obtained, it is appropriate to use $\mathrm{R} 410 \mathrm{~A}$ in the vapor compression refrigeration system for working conditions in this study.

\section{$\underline{\text { ORCID }}$ \\ B. Kılıç \\ O. İpek}

$0000-0002-8577-1845$

0000-0002-7069-1615

\section{References}

[1] Çengel, A.Y. and Boles, A.M. Thermodynamics: An Engineering Approach, New York, McGraw-Hill, 1994.

[2] Tejaswi, S.P., Pranay, K.G.S., Sai, L.P., Sachu, S.N., and Raja, S.D. 2017. Experimental evaluation mechanical performance of the compressor with mixed refrigerants R-290 and R-600a. Energy Procedia, 109, 113-121.

[3] Ki-Jung, P. and Dongsoo, J. 2008. Performance of R290 and R1270 for R22 applications with evaporator and condenser temperature variation. Journal of Mechanical Science and Technology, 22, 532-537.

[4] Luiz, H.P.M., Raiza, B.C.N., Stella, M.R.C., Hugo, V.A. and José, V.H.A. 2019. Thermodynamic performance evaluation of a cascade refrigeration system with mixed refrigerants: R744/R1270, R744/R717 and R744/RE170. International Journal of Refrigeration, 106, 201-212.

[5] Jatinder, G. and Jagdev, S. 2018. Component-wise exergy and energy analysis of vapor compression refrigeration system using mixture of R134a and LPG as refrigerant. Heat and Mass Transfer, 54, 1367-1380.

[6] Kılıçarslan, A., Tetik, T. and Kurtbaş, İ. Azeotropik ve yakın azeotropik soğutucu akışkan karışımlarının karşılaştırılması. X. Ulusal Tesisat Mühendisliği Kongresi, 13-16 Nisan 2011, İzmir, Türkiye, 10911099.

[7] Yılmaz, F., Selbaş, R. and Üçgül, İ. 2014. Ejektörlü soğutma sisteminin teorik olarak incelenmesi. Süleyman Demirel Üniversitesi Yekarum E-Dergi, 2(2), 26-33.

[8] Kılıç, B., Şencan Şahin, A. and İpek, O. İki kademeli ekonomizerli buhar sıkiştırmalı soğutma çevriminin performans analizi. X. Ulusal Tesisat Mühendisliği Kongresi, 13-16 Nisan 2011, İzmir, Türkiye, 13291334.

[9] Sun, Z., Wang, Q., Xie, Z., Liu, S., Su, D. and Cui, Q. 2019. Energy and exergy analysis of low GWP refrigerants in cascade refrigeration system. Energy, 170, 1170-1180. 
[10] Dopazo, J.A. and Fernández-Seara, J. 2011. Experimental evaluation of a cascade refrigeration system prototype with $\mathrm{CO} 2$ and $\mathrm{NH} 3$ for freezing process applications. International Journal of Refrigeration, 34(1), 257-267.

[11] Da Silva, A., Bandarra Filho, E.P. and Antunes, A.H.P. 2012. Comparison of a R744 cascade refrigeration system with R404A and R22 conventional systems for supermarkets. Applied Thermal Engineering, 41, 30-35.

[12] Kasi, M.P. 2015. Simulation of thermodynamic analysis of cascade refrigeration system with alternative refrigerants. International Journal of Mechanical Engineering and Technology, 6(1), 71-91. 